Article

\title{
"Separation of Vehicle and Battery" of Private Electric Vehicles and Customer Delivered Value: Based on the Attempt of 2 Chinese EV Companies
}

\author{
Shuxia Yang ${ }^{1, *}$, Ruoyang $\mathrm{Li}^{2}$ and Jialin $\mathrm{Li}^{3}$ \\ 1 Beijing Key Laboratory of New Energy and Low-Carbon Development (North China Electric Power \\ University), Beijing 102206, China \\ 2 State grid Beijing Electric Power Company, Beijing 100054, China; bjlry62120626@126.com \\ 3 Energy policy research center, Beijing University of Technology, Beijing 100124, China; iceylj1@126.com \\ * Correspondence: yshx@ncepu.edu.cn; Tel.: +86-136-8113-9160
}

Received: 7 February 2020; Accepted: 4 March 2020; Published: 6 March 2020

\begin{abstract}
Electric vehicles are an effective tool to reduce vehicle born emissions from road transportation. Faced with major pollution issues, China is committed to vigorously promoting electric vehicles. China has made active efforts in subsidies, policies, charging facilities, business models, etc., so that the annual growth rate of electric vehicle sales has accelerated. State subsidies have greatly promoted the use of electric vehicles, but the government is gradually reducing subsidies. In the case of government subsidy decline or even zero subsidy, "separation of vehicle and battery" is considered to be a good mode for solving the development of private EVs. The battery of an electric vehicle does not form a whole with the chassis, but they could be physically separated, replacing the battery with one which is fully charged instead of charging by users themselves, substituting battery leases for battery purchases, called separation of vehicle and battery. However, a series of issues such as whether this mode is beneficial to consumers, whether it has competitive advantages for vehicle companies, and what difficulties exist need to be further studied. This paper firstly analyzes whether it is necessary to implement "separation of vehicle and battery" for private electric vehicles (SEPARATION) in China. Based on this, it sums up the attempts of two companies to implement SEPARATION and extracts the key factors involved in SEPARATION. Then, such key factors are analyzed, and the customer delivered value model of SEPARATION is established. Finally, this article discusses the predicament of SEPARATION and makes some recommendations for the implementation of SEPARATION in China. The innovations in this paper include: (1) Analyzing the issue of SEPARATION from the perspective of customer delivered value. (2) Proposing a customer delivered value model of SEPARATION for the first time. (3) Proposing a two-level battery replacement network in the SEPARATION mode.
\end{abstract}

Keywords: separation of vehicle and battery; private electric vehicles; customer delivered value

\section{Introduction}

With severe environmental pollution and climate warming in China, road transportation has an inescapable responsibility [1], and electric vehicles may be the only sustainable transportation option [2]. According to the statistics of the Transportation Management Bureau of the Ministry of Public Security of China, as of the end of 2018, China's electric vehicle (EV) holdings reached 2.61 million, the total proportion of EVs accounts for $1.09 \%$ of the total number of vehicles, compared with 2017, an increase of 1.07 million, a growth of $70.00 \%$. From the statistics, the average annual EV number in the past five years has increased by 500,000 units, showing an accelerated growth trend. Although the growth rate of EVs is high, the proportion of total EVs is still low, and increasing the 
number of EVs is still a major problem that China is facing. There have been some research results in increasing the EV ownership.

Government subsidies are considered to be one of the effective ways to promote the consumption of electric vehicles, and detailed research on government subsidy methods and regulatory systems is conducted. Sun (2016) proposed that the fixed subsidy mechanism can effectively reduce the actual consumer price and accelerate the promotion of EVs [3]. Liu et al. (2014) believed that the government should provide subsidies for electric vehicles in the form of corporate subsidies and cash back (in the initial stage) and establish a sustainable subsidy financing mechanism and an effective subsidy supervision system [4]. Through research, Wang et al. (2013) found that the government should provide direct price subsidies and reduce the interest rate of bank loans to buy vehicles, thereby promoting consumer bank loans to buy vehicles [5]. Cho and Blommestein (2015) believed that to increase the use of EVs, it is necessary to reduce the price of electric vehicles, increase the price of fuel so that consumers have to adopt alternatives to fuel vehicles, and increase the intensity of rewards [6]. The research on government subsidies is relatively mature, and these results have played a great role in guiding the practice. Subsidies have definitely stimulated the sales of electric vehicles in the past, but subsidies cannot always exist. At present, the state has implemented a subsidy decline policy, and we should think about how to increase the number of electric vehicles in the situation which involves the decrease of subsidies or even zero subsidies.

National policies could play a certain role in promoting electric vehicle sales. Norway has used incentives to promote the use of electric vehicles [7]. Free charging services could accelerate the early promotion of EVs [8]. Through research, $\mathrm{Ma}$ (2014) believed that the government formulates supporting policies that are compatible with business model innovation, encouraging the development of business mode, and properly handles the interests of power grids, operators, vehicle manufacturers, merchants, and battery suppliers. This helps to establish a supporting system for the sustainable development of the electric vehicle industry chain, thereby promoting the development of EVs [9]. Zhang (2015) believed that the government should adjust industrial supporting policies [10]. Both Wang (2012) and Zhang (2019) believed that the government should formulate an industrial policy system, clarify the development goals of the charging facility industry, formulate a reasonable market guidance and access mechanism, and build a system of preferential tax [11,12]. Zhao (2015) and Mo (2018) both believed that the government should formulate more specific policies and regulations from the perspective of supply, environment, and demand, respectively, to encourage more entities to participate in innovation, thereby promoting the further development of EVs $[13,14]$. The government should combine taxation and subsidies to reduce the cost of EV purchases and promote the use of EVs by businesses and individuals [15,16]. The government should develop technical standards and test systems [17]. It is undeniable that these research results involve all aspects of national policy. These views are more in line with China's reality, and the way of thinking reflected in the research results and the policy elements involved will provide a reference for the study of this paper.

The completeness of basic conditions such as EV use efficiency and charging station utilization and layout are the basis for the development of electric vehicles. Increasing the number of available charging infrastructures is the most important means of reducing mileage anxiety [18]. Feng (2013) proposed a model for planning scheme optimization based on minimizing the social cost and found that reasonable configuration of charging stations can not only provide customers with better services, but could also make better use of charging station resources [19]. Zhang (2015) found through research that the charging infrastructure has very significant quasi-operational characteristics. The maximum matching of the collective optimal on the demand side can reduce costs and accelerate the promotion of EVs [20]. Both Wang (2012) and Gong (2016) believed that the construction of charging facilities network should give priority to meeting the needs of the city and be consistent with the planning of the transportation distribution network [11,15]. Morrissey et al. (2016) found that an increase in the coverage of public fast charging facilities will only further increase the market share of EVs [21]. Li et al. (2018) found that an adequate charging infrastructure is critical, and high subsidies are not necessary 
to appeal to consumers [22]. Matzner et al. (2016) believed that automobile charging infrastructure should be widely established, P2P SCC services should be used in developed areas to fully share certain resources, and PIC services should be used in underdeveloped areas [23]. The research results on the use efficiency of EVs and the use and layout of charging stations rank first in all kinds of research on electric vehicles, and it has been agreed that an improvement in convenience will increase the consumption of electric vehicles. Indirectly, it indicates that convenience of use has affected customer delivered value, which is the significance for the study of this paper.

The business model is another issue closely related to EV ownership. Ever since China advocated the development of EVs, people have been continuously exploring suitable business models. Gong (2016) believed that leased outlets and financial lease modes should be encouraged for more consumers to accept the use of EVs [15]. Ma (2014) and Zhang (2015) proposed that cities and regions with slow development of new energy vehicle markets, such as second- and third-tier cities, should be encouraged for vehicles to carry out various forms of business model innovation and increase consumers' enthusiasm for purchasing and using electric vehicles $[9,10]$. Free charging can encourage people to use EVs, but this is not a sustainable business model [24,25]. Wang et al. (2013) believed that the transaction model should be changed and the battery and vehicle separation model can be adopted [5]. Better Place and Tesla were the early companies to implement replacing battery mode. Better Place's mode failed because of its low profit, slow extension speed, high cost of battery replacement stations, and the lack of substantial government support. There are two reasons for the failure of Tesla's replacing battery mode. The first is that the service is more expensive than gas vehicles', and the other is that it's troublesome to replace the battery [26,27]. The research results propose a variety of EV business models. Although each mode has its own advantages and disadvantages, a good business mode helps to increase EV ownership. In many business modes, the separation of the battery from the vehicle is a new mode that is considered to solve the bottleneck of EV development.

In summary, (1) improving EV ownership involves government subsidies, national policies, business models, the use and layout of charging stations, and ease of use. There is a certain correlation between these aspects. Changing one aspect will cause changes in other aspects, or changes in each aspect will require other aspects to make relevant adjustments. (2) In the case of government subsidy decline and even zero subsidies, "separation of vehicle and battery" is considered to be a good model for solving the development of private EVs. However, whether this model is beneficial to consumers and whether it has competitive advantages for vehicle companies requires further research. (3) The above-mentioned research on issues such as national policies, charging station utilization and layout, and ease of use involved in increasing EV ownership are all based on the current government subsidy model. These achievements lay the foundation for research on the issues related to SEPARATION.

According to Philip Kotler's theory, mode innovation and reconstruction should be implemented to provide more (newer) value to customers. In Philip Kotler's classic marketing theory, the theory of maximum customer delivered value explains this principle. Customers are not simply price sensitive, but value sensitive. They will follow the principle of maximizing their own delivered value while selecting a product.

Customer delivered value is related to the competitiveness of the enterprise. Philip Kotler believes that consumers will choose the merchants with the highest customer delivered value for trade. Therefore, customer delivered value becomes a powerful tool for enterprises to win over customers, to defeat competitors, and to increase their market share of products [28]. Xiang (2017) proposed that the best way for convenience stores to gain greater competitive advantage in the current market environment is to provide a higher customer delivered value for consumers [29]. Ni and $\mathrm{Li}$ (2015) combined the actual situation of the refined oil industry and proposed that the enterprises could obtain the maximum customer delivered value from the customer value and the cost, so as to improve the competitiveness of oil enterprises in the market [30]. Sun (2016), taking life insurance companies as the object, suggested that such companies coordinate the total value and the total cost of customers so 
that the products of life insurance companies can continue to meet the demand and expand corporate income [31].

The key factors of customer delivered value have been studied in the literature. Nasution et al. (2011) used a structural equation model to analyze survey data and found that innovation and customer value are the most important driving forces for hotels [32]. Meng (2016) built a free marketing value model based on customer delivered value and set the total value of free marketing including product, currency, experience, psychology, and other value dimensions. The total cost of free marketing included attention, psychology, search, personal information, and other cost dimensions [33]. O'cass and Ngo (2012) suggested that customer value is crucial when creating customer delivered value for customers through innovation and marketing in a B2B environment [34]. Xie et al. (2013), when analyzing the customer delivered value of a postal parcel service, believed that the service and personnel value of the postal service was conducive to the improvement of its image value. Time and energy cost had little impact on the total cost of the postal parcel service, while time cost indirectly affected the total cost of customers [35]. When Huang and Chen (2015) analyzed the customer delivered value of online platform crowdfunding projects, they found that product value and personnel value had an impact on them, and image value had the most significant impact [36].

Scholars use different methods to analyze the customer delivered value. $\mathrm{Hu}$ (2012) established the theoretical framework of telecom customer value analysis by analyzing customer satisfaction and post-purchase behavior [37]. Xiao (2007) quantitatively studied the relationship between the change of customer delivered value and the increase of enterprise cost input [38]. Xu (2012) took Philip Kotler's customer delivered value as the theory and used comparative study and statistical analysis to study consumers' perception of customer delivered value between domestic and imported car brands [39]. Yang and Feng (2012) summarized the elements of customer value in the real estate industry and proposed the formation mechanism of the comprehensive value of the real estate industry based on customer value [40]. Han (2009) discussed the influence of customer interest and monetary cost in customer delivered value on consumer decision when quantity demanded and the direction demand change [41]. Guo (2010) took catering enterprises as the research object, and based on the experience marketing theory and customer delivered value theory, constructed an experience marketing conceptual model based on customer delivered value [42].

Summing up the representative research results of customer delivered value, we can get: (1) The foothold of enterprise competition is customer delivered value. The research on customer delivered value can measure the competitive advantage of enterprises. (2) Customer value and customer cost in customer delivered value are decided by key factors. Because of different research objects, the key factors that constitute customer value and customer cost are different. (3) Customer delivered value can be used to analyze business models, customer satisfaction, consumer decision-making, and other issues. Research on the customer delivered value of a business model is also the cornerstone to measure the existence of a business model. (4) There are qualitative methods and quantitative methods to study customer delivered value.

On the basis of the research results of increasing EV ownership and customer delivered value, this paper explores the feasibility of the "separation of vehicle and battery" mode of private EVs by studying the customer delivered value of SEPARATION. In addition, learning the lessons of Better Place and Tesla, this article discusses the dilemmas after the SEPARATION and makes recommendations for the implementation of SEPARATION in China.

The main areas researched in this paper are (1) whether it is necessary to implement SEPARATION in china, (2) the SEPARATION mode of two automakers, (3) customer delivered value on SEPARATION, (4) the difficulties in SEPARATION, and (5) suggestions on SEPARATION in China.

The paper is organized as follows. Section 2 is related to processing methods. Section 3 analyzes the key factors of customer delivered value of SEPARATION and qualitatively studies the customer delivered value of SEPARATION. Section 4 analyzes the dilemma of SEPARATION in China. Section 5 makes the conclusions and some suggestions. 
The data of this study are partly from the data published by the government and partly from non-academic sources, such as industry reports, websites, media reports, press conferences and interviews with relevant people.

\section{Methods}

\subsection{Research Ideas}

In this section, firstly, an analysis of the necessity of implementing the SEPARATION is given through data, and secondly, the separation cases of two enterprises are introduced. From the cases, the key factors involved in SEPARATION are extracted. According to Kotler's theory of customer delivered value, a customer delivered value analysis model of SEPARATION is established. Thirdly, on the basis of the key factors of the changes of SEPARATION, combined with a customer delivered value analysis model of SEPARATION, customer delivered value could be obtained.

\subsection{Why SEPARATION Should Be Implemented?}

This paper analyzes the top eight brands in China's domestic EV rankings [43]. The ranking of domestic EVs is mainly based on data from major automobile portals (power source, configuration, cost-effectiveness), vehicle popularity, and comprehensive word-of-mouth of vehicle owners, and is compiled by the "MAIGOO Networks". The relevant parameters of these eight brand EVs are shown in Table 1. This paper analyzes eight brands of EVs from the aspects of battery and use environment. As China's subsidies for the purchase of EVs are decreasing and the subsidies will soon be cancelled, the EV prices involved in this article are based on manufacturer-guided prices without special instructions. 
Table 1. Pure electric vehicle TOP8 in China related parameters.

\begin{tabular}{|c|c|c|c|c|c|c|c|c|}
\hline No. & 1 & 2 & 3 & 4 & 5 & 6 & 7 & 8 \\
\hline Company & BAIC & $\mathrm{NIO}$ & BYD & BAIC & Jili & Rongwei & Qirui & Qirui \\
\hline Brand & EX360 & ES8 & SongEV400 & EC200 & DihaoEV450 & ERX5 & Ruihu3xe & EQ1 little ants 400 \\
\hline Characteristics & SUV & $\begin{array}{l}\text { High-performance } \\
\text { smart 7-seater } \\
\text { SUV }\end{array}$ & $\begin{array}{c}\text { Professional class } \\
\text { SUV }\end{array}$ & Minicar & Mid-range vehicle & SUV & $\begin{array}{l}\text { High quality and } \\
\text { super long } \\
\text { endurance SUV }\end{array}$ & Minicar \\
\hline $\begin{array}{l}\text { Vehicle prices ( } 10 \\
\text { thousand yuan) }\end{array}$ & $18.39-20.29$ & $44.8-54.8$ & $26.41-27.41$ & $15.88-16.48$ & $21.83-23.83$ & $27.18-29.68$ & $15.78-18.98$ & $13.41-14.41$ \\
\hline $\begin{array}{c}\text { Battery warranty policy } \\
\text { (year or } 10,000 \mathrm{~km})\end{array}$ & 8 or15 & there is no limit & 8 or 15 & 8 or 15 & 8 or 15 & 8 or 12 & 8 or 12 & 8 or 12 \\
\hline Slow charging time & $7.5(h)$ & $8.0-10(\mathrm{~h})$ & & $8(\mathrm{~h})$ & $9(\mathrm{~h})$ & 7 (h) & $6.0-8.0(\mathrm{~h})$ & $7(\mathrm{~h})$ \\
\hline Quick charging time & $\begin{array}{l}\text { The charging time } \\
\text { of power from } 0 \text { to } \\
80 \% \text { is } 0.5 \text { hours }\end{array}$ & 1.1 hours & 1.2 hours & $\begin{array}{l}\text { The charging time of } \\
\text { power from } 30 \% \text { to } \\
80 \% \text { is } 36 \mathrm{~min}\end{array}$ & $\begin{array}{l}\text { The charging time of } \\
\text { power from } 30 \% \text { to } \\
80 \% \text { is } 0.5 \text { hours }\end{array}$ & $\begin{array}{l}\text { The charging time } \\
\text { of power from } 0 \\
\text { to } 80 \% \text { is } 40 \mathrm{~min}\end{array}$ & $\begin{array}{l}\text { The charging time } \\
\text { of power from } 0 \text { to } \\
80 \% \text { is } 0.5 \text { hours }\end{array}$ & $\begin{array}{l}\text { The charging time } \\
\text { of power from } 0 \text { to } \\
80 \% \text { is } 0.5 \text { hours }\end{array}$ \\
\hline Battery type & Lithium battery & Lithium battery & Lithium battery & Lithium battery & Lithium battery & Lithium battery & Lithium battery & Lithium battery \\
\hline Battery capacity & $48 \mathrm{kWh}$ & $70 \mathrm{kWh}$ & $61.9 \mathrm{kWh}$ & $20.5 \mathrm{kWh}$ & $52 \mathrm{kWh}$ & $48.3 \mathrm{kWh}$ & $49 \mathrm{kWh}$ & $38 \mathrm{kWh}$ \\
\hline $\begin{array}{c}60 \mathrm{~km} / \mathrm{h} \text { constant speed } \\
\text { range }(\mathrm{km})\end{array}$ & 398 & 500 & 400 & 200 & 450 & 425 & 445 & 301 \\
\hline Range (km) & 327 & 355 & 360 & 162 & 400 & 320 & 351 & 251 \\
\hline Time to market & 2018.03 & 2017.12 & 2018.03 & 2017.08 & 2018.02 & 2017.11 & 2018.03 & 2018.07 \\
\hline
\end{tabular}

\subsubsection{Batteries}

(1) Difference in the prices of power system

The price of the same type of fuel vehicle is shown in Table 2. Compared with the price of EVs, it is found that the price of existing pure electric vehicles is on average higher than the price of fuel vehicles.

Table 2. The price of the same type of fuel vehicle.

\begin{tabular}{|c|c|c|c|c|c|c|c|c|}
\hline No. & 1 & 2 & 3 & 4 & 5 & 6 & 7 & 8 \\
\hline Company & BAIC & $\mathrm{NIO}$ & BYD & BAIC & Jili & Rongwei & Qirui & Qirui \\
\hline Brand & EX360 & ES8 & SongEV400 & EC200 & DihaoEV450 & ERX5 & Ruihu3xe & EQ1 little ants 400 \\
\hline Corresponding fuel vehicle & $\begin{array}{l}\text { All types of X35 } \\
\text { fuel vehicle }\end{array}$ & No corresponding & $\begin{array}{l}\text { All types of song } \\
\text { fuel vehicle }\end{array}$ & No corresponding & $\begin{array}{l}\text { All types of Dihao } \\
\text { fuel vehicle }\end{array}$ & $\begin{array}{l}\text { All types of RX5 } \\
\text { fuel vehicle }\end{array}$ & $\begin{array}{l}\text { All types of Ruihu3x } \\
\text { fuel vehicle }\end{array}$ & Qirui 3 (minicar) \\
\hline $\begin{array}{l}\text { Fuel vehicle prices (10 } \\
\text { thousand yuan) }\end{array}$ & $6.58-8.88$ & & $7.99-12.99$ & & $6.98-10.08$ & $9.98-18.88$ & $4.99-6.29$ & $5.99-7.99$ \\
\hline EV prices (10 thousand yuan) & $18.39-20.29$ & $44.8-54.8$ & 26.41-27.41 & $15.88-16.48$ & $21.83-23.83$ & $27.18-29.68$ & $15.78-18.98$ & $13.41-14.41$ \\
\hline
\end{tabular}

Source: Car home website (https://www.autohome.com.cn/4080/price.html\#pvareaid=3454455). 
Take the BAIC EX360 as an example. The fueled EX360 is priced at $65,800-88,800$ yuan, while the EV version of the BAIC new energy EX360 is priced at 84,900-103,900 yuan after the state subsidies and 183,900-202,900 yuan without state subsidies. Compared with the fuel version, the price is much higher. This is not only the case for BAIC EX360, as can be seen from Tables 1 and 2. For the EV and the fuel vehicle in the same type, the price between them is more than 100,000 yuan, and part of this difference results from different dynamic power systems.

(2) Battery cost

Regarding the manufacturing cost of automotive batteries, the auto companies generally do not announce the cost or only give a vague estimation. The production cost of lithium batteries in 2017 was generally estimated at about $\$ 200 / \mathrm{kWh}$, which is 1300 yuan per kilowatt-hour [44]. Based on this data, the battery cost of eight brands of EVs is calculated, and the results are shown in Table 3.

From the calculation of the cost of batteries, it can be seen that the main reason for the high price of electric vehicles is the high cost of batteries. About $16-40 \%$ of the price of electric vehicles bought by users comes from batteries. Therefore, when the value of the vehicle body and battery is separated or the battery usage mode is changed, it could greatly reduce the purchase cost of the vehicle.

(3) Value of batteries

Li Yixiu, deputy general manager of Beijing New Energy Automobile Co., Ltd., believes that about $50 \%$ of the cost of electric vehicles comes from batteries. When electric cars are used for 3-5 years, the actual value of the battery used by the user is only about $30 \%$, and $70 \%$ of the battery value is wasted. Even if the vehicle is finally sold, the buyback value of this battery is only about $10 \%$ [45].

(4) Life of battery

Eight brands of EVs use lithium-ion batteries. The typical life of a powered lithium-ion battery is about 20 years. However, when the capacity of the vehicle's power lithium battery decreases below $80 \%$, the cruising range of the electric vehicle decreases sharply, which cannot meet consumer travel requirements. The actual use time is about $3-8$ years or 120,000 to 150,000 kilometers. If a battery is replaced after the endurance is reduced, it can be seen from Table 2 that the battery cost will be very high, and some type will reach $40 \%$ of the vehicle purchase cost, which greatly increases the cost of EV use.

(5) Charging efficiency

As can be seen from Table 1, slow charging of EV takes 7-9 hours, with a minimum of 6 hours and a maximum of ten in China. For fast charging, it takes 0.5 hours to reach $80 \%$ and $1-2$ hours to fill. Both slow charge and fast charge take longer than refueling time.

\subsubsection{EV Ecosystem}

\section{(1) Inconvenient charging}

As of June 2018, China has built 305,200 private charging stations, 271,800 public charging stations, of which 225,200 are public stations (open to the public) and 49,300 are dedicated stations (used internally by the organization) [46]. Nearly $65 \%$ of consumers do not have the conditions to install charging stations at home, and electric vehicles are always waiting in line to be recharged in front of the fast charging stations [47]. Based on the national EV inventory of 2.61 million in 2018, the ratio of EV ownership to private charging stations is 8.1: 1, and the ratio of EV ownership to public charging stations is 4.35: 1 . Compared with the sales of new energy vehicles, the construction speed of charging stations is seriously delayed, and the problem of difficult charging has always existed. 
Table 3. Battery cost of eight brands of EVs.

\begin{tabular}{|c|c|c|c|c|c|c|c|c|}
\hline No. & 1 & 2 & 3 & 4 & 5 & 6 & 7 & 8 \\
\hline Company & BAIC & $\mathrm{NIO}$ & BYD & BAIC & Jili & Rongwei & Qirui & Qirui \\
\hline Brand & EX360 & ES8 & SongEV400 & EC200 & DihaoEV450 & ERX5 & Ruihu3xe & $\begin{array}{l}\text { EQ1 little } \\
\text { ants } 400\end{array}$ \\
\hline Vehicle prices (10 thousand yuan) & $18.39-20.29$ & $44.8-54.8$ & $26.41-27.41$ & $15.88-16.48$ & $21.83-23.83$ & $27.18-29.68$ & $15.78-18.98$ & $13.41-14.41$ \\
\hline Battery capacity (kWh) & 48 & 70 & 61.9 & 20.5 & 52 & 48.3 & 49 & 38 \\
\hline Battery cost (10 thousand yuan) & 6.24 & 9.1 & 8.047 & 2.665 & 6.76 & 6.279 & 6.37 & 4.94 \\
\hline Battery cost ratio (\%) & $33.93-30.75$ & $20.31-16.06$ & $30.47-29.36$ & $16.78-16.17$ & $30.97-28.37$ & $23.19-21.16$ & $40.37-33.56$ & $36.84-34.28$ \\
\hline
\end{tabular}

Source: compiled according to news reports. 
(2) Mileage anxiety

The survey data released by the National User Committee of China Quality Association recently showed that the complaint rate of new energy vehicle users is very high. Among them, the highest level of complaints about battery is life [48]. The attenuation problem of lithium-ion battery capacity has not been solved, and fast charging has further affected the battery life, resulting in greatly reduced vehicle mileage in the later stages of use. Therefore, although the battery capacity has increased a lot, the battery's capacity decay problem has caused consumers to have "endurance anxiety" and the charging conditions are not very mature, which has increased the mileage anxiety of electric vehicle owners. At the same time, turning on the air-conditioning in winter and summer makes vehicle owners worry about mileage.

(3) Power grid pressure

Fast charging can solve the problem of slow charging to a certain extent. In the early stage of the development of electric vehicles, there were fewer electric vehicles, and the base for overcharging or fast charging was low, which had less impact on the power grid. However, with the rapid increase in the number of electric vehicles, fast charging stations will inevitably cause greater disturbance to the power grid. Therefore, fast charging cannot be the only technology for the development of electric vehicles. It is necessary to find an alternative to fast charging to solve the EV battery charging mode.

\section{3. "Separation of Vehicle and Battery" Mode of Two Automakers}

From the perspective of EV battery and use environment, in order to make private EV owners have no worries, it is necessary to solve the problems of high price for vehicle, high battery cost, low charging efficiency, inconvenient charging, mileage anxiety, and grid pressure. Therefore, Chinese private EVs can try to implement "separation of vehicle and battery".

\subsubsection{NIO's "Separation of Vehicle and Battery" Mode}

NIO is a global smart electric vehicle company, established in November 2014. On December 16, 2017, the NIO Automotive ES8 officially released the implementation of the "separation of vehicle and battery" mode. The specific parameters of the vehicle are shown in Table 1. The NIO energy cloud, based on cloud services and big data, connects charging stations, battery replacement stations, charging vehicles, batteries, ES8, and NIO commissioners and users into a smart energy Internet, whereby the users can use their cell phone or computer to buy electricity using this Internet service at any time.

(1) Vehicle purchase price and battery usage plan

The NIOES8 vehicle purchase price and battery usage plan is shown in Table 4.

Table 4. NIO ES8 vehicle purchase price and battery usage plan.

\begin{tabular}{|c|c|c|c|c|}
\hline No. & Parameter & & mber & Note \\
\hline \multirow{2}{*}{1} & \multirow{2}{*}{ Vehicle prices } & Buy a vehicle with cash only & Loans to buy vehicles & \multirow{2}{*}{$\begin{array}{l}\text { The duration of the loan is } \mathrm{X} \text {, with a } \\
\text { maximum of } 36 \text { months. NIO will } \\
\text { subsidize } 1280 \text { yuan * }(78-\mathrm{X}) \text { to users }\end{array}$} \\
\hline & & $\begin{array}{l}\text { The price of the whole vehicle } \\
\text { is reduced by } 100,000 \text { yuan }\end{array}$ & $\begin{array}{l}\text { Start the battery rental program } \\
\text { after the loan expires }\end{array}$ & \\
\hline 2 & Battery rent (RMB/month) & 1280 & 1280 & \\
\hline 3 & Battery lease period (month) & 78 & 78 months minus the loan period & \\
\hline
\end{tabular}

(2) Battery replacement scheme

After the implementation of the "separation of vehicle and battery", the NIO ES8 battery replacement plan is shown in Table 5 . 
Table 5. NIO ES8 battery replacement plan.

\begin{tabular}{|c|c|c|c|c|c|}
\hline No. & & & 2 & 3 & 4 \\
\hline \multirow{2}{*}{ Parameter } & \multicolumn{2}{|c|}{ Package fee (optional) } & \multirow{2}{*}{$\begin{array}{l}\text { "Powered up with one } \\
\text { click" service (time/month) }\end{array}$} & \multirow{2}{*}{ Free charge (KWh/month) } & \multirow{2}{*}{ Free battery upgrade } \\
\hline & (Yuan/year) & (Yuan/month) & & & \\
\hline Note & & & $\begin{array}{l}\text { Specially-assigned person } \\
\text { to pick up and deliver the } \\
\text { vehicle and replace the } \\
\text { battery for the owner }\end{array}$ & $\begin{array}{c}\text { It is used to offset the charges } \\
\text { when one-key power charging, } \\
\text { home charging and } \\
\text { public charging }\end{array}$ & $\begin{array}{l}\text { After the battery is } \\
\text { upgraded by NIO, the } \\
\text { upgraded battery can be } \\
\text { used for free }\end{array}$ \\
\hline
\end{tabular}

Source: official website of NIO.

(3) NIO's battery replacement station

On 20 May 2018, NIO's first national battery replacement station was completed in Nanshan, Shenzhen. When the EV needs to be recharged, it will pull into the battery replacement station and the battery that needs to be recharged is replaced with a battery that has been fully charged in the station. Since then, stations have also been established in Guangzhou, Beijing, Changsha, Suzhou, and other cities. The parameters of the stations are shown in Table 6. On 15 November 2018, NIO announced the official completion of the battery replacement network for the Beijing-Hong Kong-Macao Expressway. The Beijing-Hong Kong-Macao Expressway is a major artery in the north and south of China, with a total length of about 2285 kilometers. A total of 18 NIO battery replacement stations are located in 14 service areas around Shijiazhuang, Zhengzhou, Wuhan, Changsha, Guangzhou, and other key cities. In 2019, NIO will focus on the construction of a backbone of high-speed battery change networks in the central and eastern regions. By 2020, NIO plans to build more than 1100 battery replacement stations across the country and launch more than 1,200 mobile charging vehicles.

Table 6. The parameters of the battery replacement station.

\begin{tabular}{cccccc}
\hline No. & $\mathbf{1}$ & $\mathbf{2}$ & $\mathbf{3}$ & $\mathbf{4}$ & $\mathbf{5}$ \\
\hline Parameter & $\begin{array}{c}\text { Construction time } \\
\text { (hours) } \\
\text { Number }\end{array}$ & $\begin{array}{c}\text { Data not available to } \\
\text { the public }\end{array}$ & $\begin{array}{c}\text { Area }\left(\mathrm{m}^{2}\right) \\
\text { Data not available to } \\
\text { the public }\end{array}$ & $\begin{array}{c}\text { Number of } \\
\text { parking vehicles }\end{array}$ & $\begin{array}{c}\text { Service number of } \\
\text { private vehicles in a day } \\
\leq 200 \text { (estimate) }\end{array}$ \\
\hline
\end{tabular}

Source: official website of NIO.

(4) Car maintenance

ES8 owners can enjoy four services including lifetime free warranty, lifetime free vehicle networking service, lifetime free remote power on, and lifetime free road rescue.

\subsubsection{BAIC's Private EV “Separation of Vehicle and Battery" Mode}

(1) Vehicle price

In July 2018, BAIC New Energy launched the first EU quick-change version of the private electric vehicle. The EU quick-change version parameters are shown in Table 7. The "separation of vehicle and battery" mode promoted by BAIC New Energy is to deeply integrate EVs, batteries, battery replacement stations, and photovoltaic power generation through battery replacement and battery reuse technologies, so as to build an intensive, intelligent, and convenient green travel ecology, This enables efficient use of energy resources throughout the EV's entire life cycle. 
Table 7. The parameters of EU quick-change version.

\begin{tabular}{|c|c|c|c|c|c|c|c|}
\hline No. & 1 & 3 & 2 & 4 & 5 & 6 & 7 \\
\hline Parameters & $\begin{array}{c}\text { Vehicle price } \\
\text { (ten thousand yuan) }\end{array}$ & Battery capacity $(\mathrm{kWh})$ & $\operatorname{NEDC}(\mathrm{km})$ & Battery replacement time & Battery type & $\begin{array}{l}\text { Maintenance cost } \\
(\mathrm{RMB} / 10,000 \mathrm{~km})\end{array}$ & Characteristics \\
\hline Number & 12.98 & 45 & 300 & $3 \min$ & Ternary lithium battery & 220 & $\begin{array}{l}\text { Both charge and battery } \\
\text { replacement function }\end{array}$ \\
\hline
\end{tabular}

Source: compiled according to news reports. 
After the government gives the subsidy for the BAIC New Energy EU quick-change (there is still a state subsidy), the vehicle's unified selling price is 129,800 yuan. After the user receives the subsidy and completes the licensing procedure, the battery property rights will be repurchased by the battery management company for 50,000 yuan, and the consumer will obtain the battery use right by leasing. Equivalent to the new vehicle (without battery) to the starting price of 129800-50000 $=79,800$ yuan.

(2) Battery usage and battery replacement scheme

The monthly battery rental fee for the EU Quick Change Edition is RMB 458. The business mode of "separation of vehicle and battery" is shown in Table 8 .

Table 8. The mode of SEPARATION of BAIC new energy company.

\begin{tabular}{ccccc}
\hline No. & Package & Package Fee (RMB/Month) & Contains the Mileages $\mathbf{( k m )}$ & Electricity Fee (Yuan/km) \\
\hline 1 & Package A & 432 & 1200 & 0.36 \\
2 & Package B & 630 & 1800 & 0.35 \\
3 & Package C & 1020 & 3000 & 0.34 \\
\hline
\end{tabular}

Note: The unused mileages of the current month can be automatically transferred to the next month for use (the balance of the current month can be extended to the next month for use and reset at the end of the next month). If you exceed the set mileages of the month, you will be charged according to the standard of $0.45 \mathrm{yuan} / \mathrm{km}$. source: official website of BAIC new energy company.

(3) Battery replacement station

Taking Beijing as an example, BAIC has built 100 battery replacement stations that are mainly based on replacing batteries and have a charging mode, forming a replacing battery radius of $2.78 \mathrm{~km}$, which can provide convenient and efficient services like gas stations.

BAIC New Energy's battery replacement station for private vehicle owners is built by transforming a container. The battery replacement station uses an L-shaped structure and covers an area of about 67 square meters. The advantage of using a container is that it can reduce costs and is easy to build, the construction of a station can be completed in 4 hours. The construction cost of a single station is about 3 million yuan, with a maximum capacity of 28 batteries. The parameters of the battery replacement stations are shown in Table 9. An investment of RMB 10 billion is expected by 2022. An estimated 3000 battery replacement stations of optical storage will be built, in more than 100 cities across the country, and 500,000 electric vehicles will be put into operation.

Table 9. The parameters of the BAIC New Energy battery replacement station.

\begin{tabular}{|c|c|c|c|c|c|c|}
\hline No. & 1 & 2 & 3 & 4 & 5 & 6 \\
\hline Parameter & $\begin{array}{l}\text { Construction } \\
\text { time (hours) }\end{array}$ & Area $\left(\mathrm{m}^{2}\right)$ & $\begin{array}{c}\text { Number of } \\
\text { parking vehicles }\end{array}$ & $\begin{array}{c}\text { Service number of } \\
\text { private vehicles in day }\end{array}$ & Service radius $(\mathrm{km})$ & Cost (10 thousand yuan) \\
\hline Number & 4 & 67.5 & 5 & $\leq 300$ & 2.78 (Beijing) & 300 \\
\hline
\end{tabular}

Source: compiled according to news reports.

In terms of technical innovation of battery replacement stations, BAIC New Energy is also in the forefront of the industry. At present, a single BAIC New Energy battery replacement station covers an area of about 100 square meters, and the number of replacing batteries per station per day can reach 216 times. It can serve more than 100 taxis (daily operation $>400 \mathrm{~km} /$ day) or about 1000 private vehicles. It is understood that the efficiency and technology of the BAIC New Energy battery replacement station are still developing continuously. The battery replacement station uses a container structure, and the area can be continuously optimized. With the improvement of technology and methods, the battery replacement station is developing from needing several people on duty to a single person on duty and even an unmanned station, which can further reduce operating costs.

(4) Repurchase of vehicles

In the "separation of vehicle and battery" mode of BAIC New Energy, the vehicle is repurchased. See Table 10 for the vehicle body repurchase scheme. 
Table 10. The vehicle body repurchase scheme.

\begin{tabular}{cccc}
\hline Plan & 1 & 2 & 3 \\
\hline $\begin{array}{c}\text { Buy-back } \\
\text { conditions }\end{array}$ & $\begin{array}{c}\text { Used time } \leq 3 \text { years, mileage } \leq 6 \\
\text { Thousands of kilometers }\end{array}$ & $\begin{array}{c}\text { Used time } \leq 3 \text { years, } 6<\text { mileage } \leq 8 \\
\text { Thousands of kilometers } \\
\text { Repurchase price }\end{array}$ & $\begin{array}{c}\text { Used time } \geq 3 \text { years, } 8< \\
\text { mileage } \leq 15 \text { housands of } \\
\text { kilometers }\end{array}$ \\
$\begin{array}{c}\text { On the basis of plan 1, depreciation is } \\
\text { calculated on the basis of the mileage } \\
\text { exceeding } 60,000\end{array}$ & $\begin{array}{c}\text { Prices are valued according to } \\
\text { the actual state of the vehicle }\end{array}$ \\
\hline
\end{tabular}

Source: compiled according to news reports.

(5) Cascade utilization of battery

The "separation of vehicles and battery" model will realize the cascade utilization of batteries in the private market, dig deeper into the value of the battery's full life cycle, promote the recyclable use of energy, and improve energy efficiency. Secondly, the new model adopts a unified battery management solution, which is more conducive to battery recycling and subsequent value development, creating more business value. Finally, all batteries will be uniformly managed and regularly maintained by the battery replacement stations, and unified slow charging will be performed in a constant temperature and humidity environment to achieve the effects of delaying battery decay and enhancing safety and reliability.

\subsection{Customer Delivered Value Analysis Model of SEPARATION}

From the above two vehicle companies' implementation of "separation of vehicle and battery" cases, the key factors involved in SEPARATION can be extracted. These include speed of battery replacement, battery life, vehicle purchase price, vehicle use cost, battery recycling, and vehicle body residual value. These key factors become the basis for analyzing the value of customer delivered value.

Customer Delivered Value $=$ Total Customer Value -Total Customer Cost. According to this theory, the customer delivered value analysis model of SEPARATION (only the factors that change after SEPARATION are listed) is shown in Figure 1.

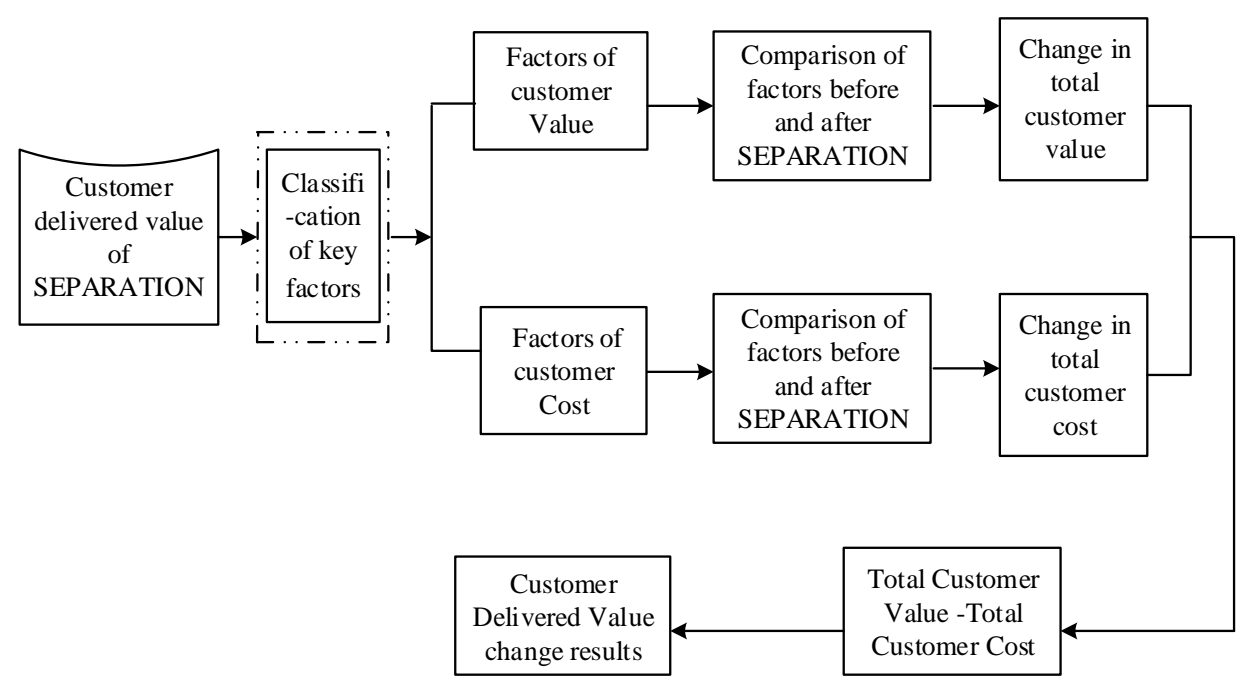

Figure 1. Customer delivered value analysis model of SEPARATION.

\section{Results}

\subsection{Analysis of Key Factors of Customer Delivered Value of SEPARATION}

(1) Speed of battery replacement 
Both vehicle companies have fully achieved the automatic replacement of battery within 3 minutes. After the vehicle enters the station, the time from removing the battery which needs to be recharged to installing a fully charged battery is 2 minutes and 46 seconds. The whole process only involves the need to scan a $Q R$ code instead of any complicated operation.

(2) Battery life

After the battery replacement mode is implemented, the batteries replaced will have a unified and standardized management. The battery is charged at a charge rate of $0.45 \mathrm{C}$ in a constant temperature environment inside the station, with $20 \mathrm{~kW}$ slow charging, and the charging power curve of each battery is monitored in real time, which can effectively guarantee the battery status and extend battery life by 2-3 times more than before the separation of vehicle and battery. Utilizing cloud big data platform to accurately trace battery status and the station data, battery use is safer. Concentrated valley floor charging has achieved a certain reduction in operating costs, and at the same time, it has contributed to the reasonable use of electricity in society through load shaping.

(3) Cost of using vehicles

Only the usage cost of the BAIC EU Quick Change Edition before and after the implementation of the battery replacement mode is calculated here.

After the consumer purchases a pure electric vehicle, the battery property rights will be repurchased by the battery management company and the consumer will obtain the battery use right by lease. Consumers can choose three different mileage packages from 1200-3000 kilometers according to their needs. Packages are not charged according to the number of replacing batteries. The billing is only calculated based on the kilometers displayed by the vehicle and has nothing to do with the remaining battery power. The battery rental price is as low as 458 yuan per month, and the electricity cost per kilometer is as low as 0.34 yuan to 0.36 yuan; the maintenance cost is as low as 220 yuan per 10,000 kilometers, and the annual operating cost is the same as the mileage.

Annual use cost after battery replacement mode $=$ annual battery rental fee + annual total electricity fee (annual driving mileage * power consumption per 10,000 kilometers * electricity price) + maintenance costs.

Annual use cost before the battery replacement mode $=$ annual battery depreciation fee + annual total electricity fee (annual driving mileage * power consumption per 10,000 kilometers * electricity price) + maintenance costs.

It is assumed that the electricity cost, maintenance cost, etc. per kilometer will not change, and the usage cost before and after the battery replacement is only reflected in the annual battery rental fee and annual depreciation fee.

The annual battery rental fee is $458 * 12=5496$ yuan. The cost of the EU quick-change battery $=$ battery capacity * battery production price $=45 * 1300=58500$ yuan. The annual battery depreciation fee is $58500 / 8=7312.5$ yuan.

It can be seen that the annual use cost before the battery replacement mode $\geq$ the annual use cost after the battery replacement mode.

Since the power consumption of the air-conditioning is not reflected in the mileage, it will not be added to the electricity replacement cost, and the user can use the air-conditioning at will. Moreover, with the leased battery, it is only necessary to pay for the mileage, and the electricity used in traffic jams is not charged, which not only provides users with convenience and comfort, but also saves a lot of expenses.

(4) Battery ownership

As the battery is leased, BAIC only charges according to mileage. Therefore, there is no need to bother with the replacement of the old and new batteries and the battery decay, and the vehicle companies will uniformly use the retired batteries in stages. Vehicle insurance covers rented batteries, and accidental damage will be covered by the insurance company. NIO does not charge by mileage; it 
charges by the number of the replacing batteries. It does not need to pay attention to the replacement of old and new batteries and battery decay. Finally, the battery retired during the battery replacement process will not and cannot be returned to the owner, although this is not explicitly stated, as it is still owned by the vehicle company.

While significantly reducing consumer vehicle purchase costs, the private battery replacement mode has deeply tapped the value of the battery's entire life cycle, realizing the battery's cascade utilization in the private market, which is beneficial to battery recycling and subsequent value development. At the same time, it can effectively delay the battery decay of private users and ensure the safety of consumers.

(5) Residual value of vehicle

In terms of vehicle residual value, BAIC New Energy has launched a three-year $50 \%$ off high-value preservation policy to relieve worries about buying a vehicle. At the same time, because the battery is rented, there is no factor of battery attenuation, which is very advantageous for the valuation of BAIC used electric vehicles. Furthermore, NIO owners can enjoy a free lifetime warranty for their vehicles, giving worry-free use. However, the residual value of the vehicle is uncertain.

(6) Vehicle purchase cost

After implementation of the SEPARATION, consumers no longer pay for battery costs, so vehicle purchase costs are generally reduced. The EU quick-change version of the vehicle purchase cost decreased from 129,800 to 79,800 yuan, and the NIO ES8 vehicle price decreased by 100,000 yuan, which better solved the price problems of electric vehicles.

\subsection{Customer Delivered Value of the SEPARATION}

According to the customer delivered value analysis model of SEPARATION and the analysis of the above key elements, we can see the dynamic reflection of the total customer value and total customer cost after the SEPARATION. The customer delivered value model of SEPARATION is shown in Figure 2. SEPARATION reduces the total cost of private EV consumers, increases the overall value of EV consumers, and increases the value of final customer deliveries. This not only benefits consumers but also gives vehicle companies a competitive advantage, so the SEPARATION mode is feasible.

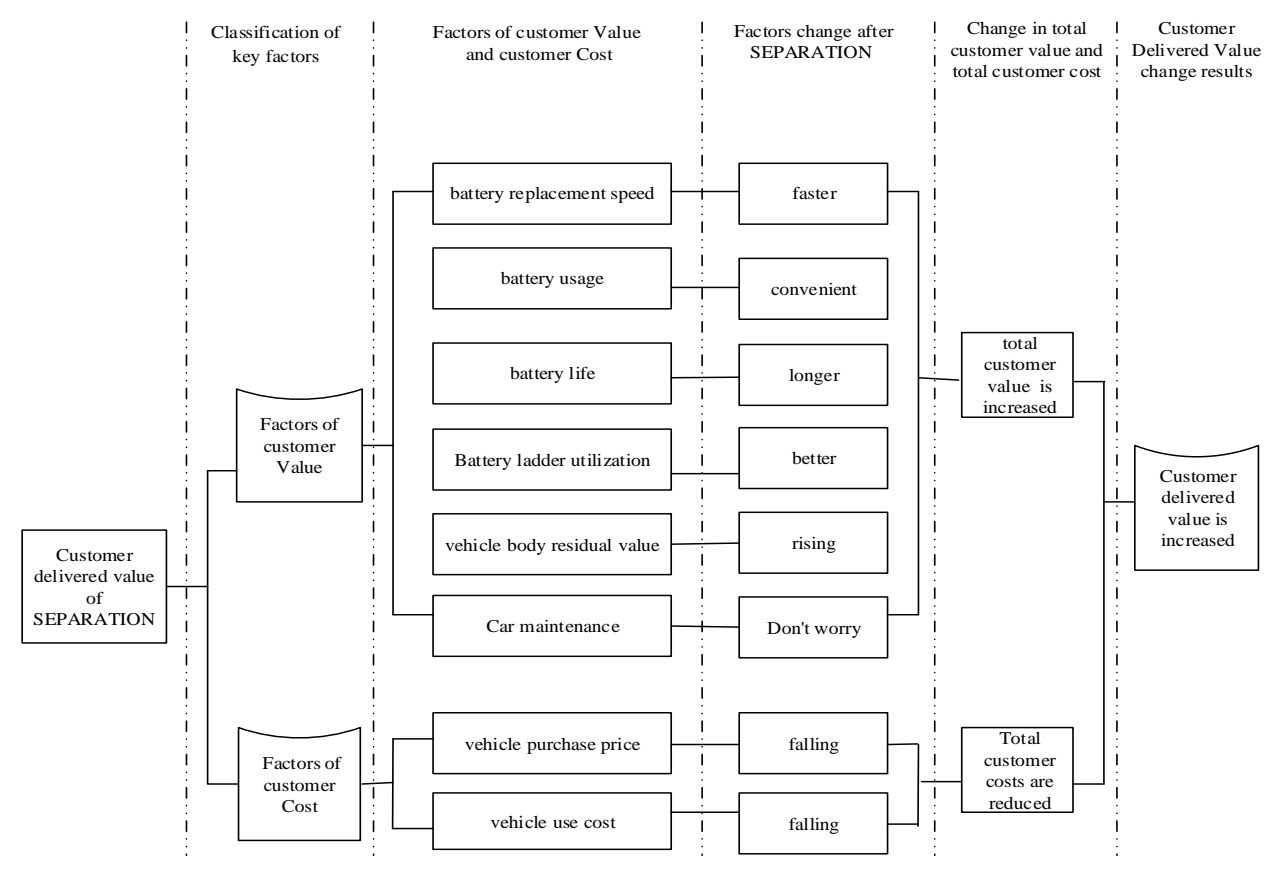

Figure 2. Customer delivered value model of the SEPARATION. 


\section{Discussion: Difficulties in the Implementation of SEPARATION}

The implementation of "separation of vehicle and battery" for private EVs has improved customer delivered value. This is a good thing, but it is also necessary to overcome the dilemmas of SEPARATION in order to better achieve the customer delivered value of "separation of vehicle and battery".

(1) Battery replacement technology

When replacing the battery, you must remove the original battery and install a new battery. This increases the wear and tear of the battery. At the same time, it is prone to loosening, which greatly increases the safety hazards of the vehicle. It is easy to cause short-circuits due to poor contact, which may cause spontaneous combustion, water leakage, etc., and increase the technical requirements of battery replacement personnel.

(2) Liability for damage of batteries

The battery is related to the safety of the vehicle, and if there is a problem, it must have a corresponding responsibility bearer. First of all, there must be clear and strict standards for the batteries that are replaced each time. Those who fail to meet the standards must not be replaced in a vehicle to avoid accidents; secondly, if a battery problem causes damage to the vehicle or the people in the vehicle, who should bear the responsibility, and how should the responsibility for damage to the vehicle during the battery replacement process be divided? Only after the related responsibilities are clearly identified in advance, can the people who are responsible be decided after an incident. Regarding how to ensure battery quality, consistency, and other quality issues, this also needs to be resolved before large-scale promotion of battery replacement.

(3) Leading mode

At present, only a few types of vehicles produced by two companies in China adopt SEPARATION, which involves restrictions on property rights of battery replacement stations. If it is to be promoted on a large scale, it also depends on how much the local government attaches importance to this aspect. However, at least for now, the relevant repair supporting services must be dominated by manufacturers, which does not rule out that manufacturers will gradually strengthen cooperation with relevant community service agencies, and then provide higher convenience for vehicle owners.

(4) Cost of battery replacement station

The battery standards of different vehicle companies are different. In order to facilitate battery replacement, each vehicle company must establish its own battery replacement station, and the distribution must be reasonable, which will obviously cause a lot of waste of capital and land resources. According to Li Yixiu, deputy general manager of BAIC New Energy, "The earliest cost of a battery replacement station was 3 million yuan, and now total cost of station and backup batteries is close to 5 million yuan. Such a heavy asset investment will become idle if there is no matching vehicle. It is a very serious problem." Although NIO did not announce the cost of a battery replacement station, it cannot be much cheaper than those built by BAIC New Energy. This also shows that the battery replacement station cannot be as big as the layout of gas stations. If it costs 5 million yuan for a battery replacement station, based on the NIO vehicle's ES8 listing conference, it is calculated that 1100 power stations in the country will be built in 2020, and a continuous investment of 5 billion yuan is needed. Obviously, it is unrealistic for auto companies to build their own battery replacement stations.

\section{(5) Convenience}

The number of battery replacement stations, or how much the distribution distance can meet the user's battery requirements, is a practical problem that requires a long time and must be solved. For users, what is key for replacing a battery is not whether it is completed within 3 minutes, but whether it is convenient to go to the battery replacement station. If the station is far from home or the 
company, part of the replacing battery will be consumed on the road. If you drive to other places, it is unknown whether you can find a battery replacement station. Even if the replacement time is short, it is meaningless to go to the battery replacement station.

(6) Insurance

To protect the interests of consumers, EVs should enjoy convenient insurance services in any mode. However, the overall insurance of the electric vehicle industry is still in the blanking period. Judging from the actual situation of electric vehicle insurance, insurance companies are still in the exploration stage of determining the damage of electric vehicles, especially batteries, and they cannot accurately determine the damage. As a result, consumers accept unreasonable premiums to some extent. After the implementation of the "separation of vehicle and battery", the battery replacement system is more complicated than the EV insurance assessment of the vehicle with battery, and this problem cannot be solved perfectly, which will affect the sales of EVs.

(7) Battery universality

As the core part of EVs, the battery has very high technical requirements. At the present stage, the batteries used by the enterprises implementing "separation of vehicle and battery" are different from each other. Because the basic parameters are not uniform and the voltage is not consistent, the interface of the battery management system and the battery's discharge power also have their own standards, which makes it impossible for the batteries of different EVs to be used interchangeably. After consumers buy the EVs where the vehicle and battery are separated, they still have to go to the corresponding battery replacement station to replace the battery, so the significance of "separation of vehicle and battery" is greatly discounted.

\section{Conclusions and Recommendations}

\subsection{Conclusions}

From the analysis of customer delivered value of SEPARATION, the following conclusions could be drawn.

(1) "Separation of vehicle and battery" helps increase EV ownership

The implementation of the "separation of vehicle and battery" directly reduces the purchase and use costs of vehicles, the residual value of second-hand vehicles is further guaranteed, and there are no worries about vehicle body disposal when vehicles are scrapped. There is no need to worry about battery life and it is convenient to replace the battery. These changes solve the problems of mileage anxiety, long charging time, and inconvenience, and will promote consumers to buy electric vehicles.

(2) "Separation of vehicle and battery" helps the battery to maximize its value

After the battery replacement, the battery can be charged by controlling the AC slow charging in the battery compartment at a constant temperature and humidity, which reduces loss and extends the battery life. For battery owners, longer battery life means longer service life and cost sharing. After the battery is retired, it will be collected by the recycling company. Under the condition that the battery life is more predictable, the cascade utilization and residual value recovery will become more secure and higher value can be realized. As the battery exerts its maximum value, it reduces environmental pollution.

(3) Battery technology and quality are the foundation of SEPARATION

The implementation of "separation of vehicle and battery" requires batteries to be versatile. The higher the universality, the lower the cost of battery production and use. Improving battery universality is inseparable from the technical guarantee. Battery replacement has very high requirements 
on technology and quality. Inferior technology will affect the life of the battery, and constant replacement also puts forward requirements on battery quality.

(4) Convenience relates to the effect of "separation of vehicle and battery"

SEPARATION is mainly to reduce costs, increase customer value and allow customers to obtain greater delivered value, but these effects are based on user convenience. In today's modern society, people's pace of life is accelerated, and the loss of convenience will increase the customer's time cost and then reduce the customer delivered value.

(5) SEPARATION is a systematic project in which the power grid, government, and vehicle companies cooperate

"Separation of vehicle and battery" should not be just vehicle company behavior. "Separation of vehicle and battery" changes the original charging mode. After the battery is replaced into the battery compartment through the replacement mode, it can be charged at the time of the valley electricity price through unified charging management, make full use of the valley electricity price, and help the power grid to achieve the function of peak cutting and valley filling. It is expected that the battery replacement station will accurately predict the power load after vehicle networking and thus become a controllable energy storage power station. In the case of the country's release of electricity sales, the peak-shaving energy storage in the capacity market and the corresponding sales of electricity in the frequency market are quite attractive, which is undoubtedly beneficial to the grid. However, because centralized charging affects the maximum load and load curve of the power grid, there is a problem of reasonable matching between vehicle companies and the power grid. A good solution to this problem requires not only the cooperation between vehicle companies and the power grid, but also the government's role in coordinating.

\subsection{Recommendations}

(1) Vehicle manufacturers should cooperate in operation

Companies that implement the "separation of vehicle and battery" are currently operating independently, and each enterprise has limited resources. This independent operating mode places higher requirements on capital. From the perspective of the construction of a battery replacement station, the basic operating cost of a battery replacement station starts from 6.8 million yuan, and the actual operating cost may be higher. Under such a high funding pressure, both the cost and convenience of battery replacement are tested. It can be seen that "separation of vehicle and battery" cannot form a market advantage for any company on its own. Coordinated operation among vehicle companies can improve convenience, reduce costs, and jointly expand the EV market.

(2) Vehicle manufacturers, the power grid, and the government should coordinate with each other

After implementing "separation of vehicle and battery" mode, the battery replacement station uses centralized charging. On the one hand, concentrated charging for the power grid, directly connecting the battery to the power grid, will inevitably increase the load demand on the power grid, affect power grid stability, and have other negative effects. On the other hand, the battery is not only a device for EVs, but also an energy storage device. The battery charging requirements can be guided and transferred, so vehicle companies should be coordinated to carry out orderly charging and load shaping. In addition, with the gradual maturity of the electricity trading spot market, the peak period of new energy generation is also the period when the spot market's electricity price is relatively low. Vehicle companies and the power grid should reflect the upstream peak-valley electricity price in the charging price of the battery replacement station through coordination, which will not only reduce the battery charging cost, but also connect new energy sources upstream.

Through the coordination of the government, the establishment of related standards for the construction and operation of electric vehicle charging and replacement facilities is promoted, with 
breakthroughs in key technical standards such as charging interfaces and standard battery boxes. The policy can guide the charging price of batteries, and the peak-to-valley spread will gradually increase in the future, so that the orderly charging of electric vehicles can fully enjoy the effect of the peak-to-valley spread. The government can also coordinate policies on taxation and finance.

(3) Standardization of battery and battery replacement system

At present, the battery specifications and battery replacement systems of different vehicle companies and different types of the same company are different, which cannot achieve universality, which restricts the popularity of battery replacement modes and coordination between vehicle companies. Therefore, the battery replacement stations oriented to "vehicle-battery separation", standard battery specifications, and cascade utilization need to have higher compatibility, which requires battery and battery replacement system standardization. After standardization is achieved, the vehicle battery replacement technology and the battery replacement network in the battery replacement system are interoperable, and the batteries are universally compatible between various vehicle companies and types. The battery replacement station should be able to provide undifferentiated services for all EVs that use "separation of vehicle and battery", laying the foundation for coordinated operations between vehicle companies.

(4) Promote suitable insurance products

Although insurance companies cover electric vehicles, there is no vehicle insurance specifically designed for electric vehicles. Electric vehicles and traditional gasoline vehicles have almost the same type of insurance. After implementation of the "separation of vehicle and battery", the vehicle body is separated from the battery and they belong to different subjects, both of which require insurance. Therefore, insurance products will differentiate the overall structure, power system, parts and maintenance technology of EVs from traditional fuel vehicles, and develop targeted insurance liability clauses based on their risk characteristics. There is no separate insurance type for power battery parts with higher risk factors and higher costs. There must be corresponding insurance products after "separation of vehicle and battery".

(5) Construct a two-level network of "battery replacement station + the affiliated station of battery replacement".

Due to the limitation of funds, the number and location of battery replacement stations may not fully meet convenience requirements, or a certain number of stations will be deployed from the perspective of reducing costs. Then, a two-level network of "battery replacement station + the affiliated station of battery replacement" will be built. The battery replacement station provides centralized storage and recharging of a large number of batteries, and provides a replacing battery service for EVs in the station. The main function of the affiliated station is to provide a battery replacement service. Its construction costs are much lower than the battery replacement station. The affiliated station is an extension of the battery replacement station's inventory space and geographical location, and it can reserve a portion of the charged battery. EV users can choose to use either a battery replacement station or affiliated station of battery replacement. With a reasonable layout, the replacing battery radius can be reduced, which can reduce the number of battery replacement stations and facilitate the EV user's battery replacement.

Author Contributions: S.Y. grasped the overall context of the article and guided and completed the creation and modification of this article as a whole. R.L. concentrated on the literature review, methods, results and discussion, analyzed the data, and contributed the analysis tools. J.L. assisted in writing and modifying the article. All authors have read and agreed to the published version of the manuscript.

Funding: The research was funded by National Social Science Foundation of China (grant number is 16BJY055).

Conflicts of Interest: The authors declare no conflicts of interests. 


\section{References}

1. Yang, S.X.; Zhang, D.; Fu, J.; Fan, S.; Ji, Y. Market cultivation of electric vehicles in China: Survey based on consumer behavior. Sustainability 2018, 10, 4056. [CrossRef]

2. Boyle, G. Renewable Energy: Power for a Sustainable Future, 3rd ed.; Oxford University Press: Oxford, UK, 2012.

3. Sun, Q.P. Influence Factors and Subsidy Strategies for the Development of Electric Vehicles. Master's Thesis, South China University of Technology, Chengdu, China, 2016.

4. Liu, Y.Q.; Wang, J.Y.; Ari, K. EV demonstration policy and business model innovation: Global experiences and China's practices. Chin. Soft Sci. 2014, 12, 1-16.

5. Wang, Y.; Jin, L.; Xiao, K.; Jia, H.G.; Li, Z.H. The Government Subsidy Research of New Energy Sedan Industry Based on the Consumer Demand. Adv. Mater. Res. 2013, 711, 446-451. [CrossRef]

6. Cho, Y.; Blommestein, K.V. Investigating the Adoption of Electric Vehicles Using Agent-based Model. In Proceedings of the 2015 Portland International Conference Management Engineering Technology, Portland, OR, USA, 2-6 August 2015; pp. 2337-2345.

7. Mersky, A.C.; Sprei, F.; Samaras, C.; Qian, Z.S. Effectiveness of incentives on electric vehicle adoption in Norway. Transp. Res. Part D Transp. Environ. 2016, 46, 56-68. [CrossRef]

8. Longo, M.; Zaninelli, D.; Viola, F.; Romano, P.; Miceli, R. How Is the Spread of the Electric Vehicles? In Proceedings of the IEEE 1st International Forum on Research and Technologies for Society and Industry Leveraging a Better Tomorrow (RTSI), Turin, Italy, 16-18 September 2015; pp. 439-445.

9. Ma, B.B. Promotion of Electric Vehicles. Master's Thesis, Xiamen University, Xiamen, China, 2014.

10. Zhang, C.L. Thinking on comprehensively promoting the development of new energy automobile industry. China Dev. Obs. 2015, 11, 71-72.

11. Wang, E.Q. Research on Business Mode and Planning of EV's Charging Facilities. Master's Thesis, North China Electric Power University, Beijing, China, 2012.

12. Zhang, X.R. Research on policy promotion mechanism optimization of technological innovation in electric vehicle industry. Manag. Adm. 2019, 05, 88-92.

13. Zhao, G.D. Research into the Innovation Policies of China's New-Energy Automobile Industry. Master's Thesis, Beijing Institute of Technology, Beijing, China, 2015.

14. Mo, S.Y. Research on the Development Strategy of China's new Energy Automobile Industry Driven by Low-Carbon Economy. Master's Thesis, Lanzhou University, Lanzhou, China, 2018.

15. Gong, L.Y. Study on New Energy Vehicles Application Strategies in Transportation Industry. In Proceedings of the 2016 2nd International Conference on Energy Equipment Science and Engineering, Guangzhou, China, 12-14 November 2016. [CrossRef]

16. Vander Steen, M.; Van Schelven, R.; Kotter, R.; Van Twist, M.; Peter van Deventer, M. EV policy compared: An international comparison of governments policy strategy towards e-mobility. In E-Mobility in Europe; Springer: Berlin/Heidelberg, Germany, 2015; pp. 27-53.

17. Habib, S.; Khan, M.M.; Abbas, F.; Sang, L.; Shahid, M.U.; Tang, H. A Comprehensive Study of Implemented International Standards, Technical Challenges, Impacts and Prospects for Electric Vehicles. IEEE Access 2018, 6, 13866-13890. [CrossRef]

18. Dorcec, L.; Pevec, D.; Vdovic, H.; Babic, J.; Podobnik, V. How do people value electric vehicle charging service? A gamified survey approach. J. Clean. Prod. 2019, 210, 887-897. [CrossRef]

19. Feng, L. Research on Charging Station Planning of Electric Vehicles. Ph.D. Thesis, Tianjin University, Tianjin, China, 2013.

20. Zhang, Y. Research on Supply and Matching of Electric Vehicle Charging Service. Ph.D. Thesis, Chongqing University, Chongqing, China, 2015.

21. Morrissey, P.; Weldon, P.; O'Mahony, M. Future standard and fast charging infrastructure planning: An analysis of electric vehicle charging behaviour. Energy Policy 2016, 89, 257-270. [CrossRef]

22. Li, W.; Yang, M.; Sandu, S. Electric vehicles in China: A review of current policies. Energy Environ. 2018. [CrossRef] 
23. Matzner, M.; Chasin, F.; Hoffen, M.V.; Plenter, F.; Becker, J. Designing a Peer-to-Peer Sharing Service as Fuel for the Development of the Electric Vehicle Charging Infrastructure. In Proceedings of the Hawaii International Conference on System Sciences, Koloa, HI, USA, 5-8 January 2016; pp. 1587-1595.

24. Harrysson, S.; Ulmefors, M.; Kazlova, A. Overview and Analysis of Electric Vehicle Incentives Applied across Eight Selected Country Markets; Technical Report; Blekinge Institute of Technology, The Department for Strategic Sustainable Development: Blekinge, Sweden, 2015.

25. Bocken, N.M.P.; Short, S.W.; Rana, P.; Evans, S. A literature and practice review to develop sustainable business model archetypes. J. Clean. Prod. 2014, 65, 42-56. [CrossRef]

26. Cheyunwang. How to Turn Better Place into a Dead End. Available online: http://www.cheyun.com/content/ 1837 (accessed on 18 June 2019).

27. Luntan. The Failure of Better Place and Tesla. Available online: http://club.autohome.com.cn/bbs/thread/ 9263471c0eda58fc/73669881-1.html (accessed on 20 June 2019).

28. Philip, T.K.; Kevin, L.K. Marketing Management; Prentice Hall: London, UK, 2011; pp. 2-125.

29. Xiang, J. On the competitive strategy of local convenience store chains to enhance customer delivery value. Bus. Econ. Res. 2017, 1, 83-87.

30. Ni, L.; Li, J. Analysis on the direct selling strategy of refined oil based on customer transfer value theory. J. Fujian Coll. Commer. 2015, 13, 29-33.

31. Sun, N.Y. Value chain and customer transfer theory model and its modification based on Chinese life insurance marketing model. New Econ. 2016, 11, 26.

32. Nasution, H.; Mavondo, F.; Matanda, M.J.; Ndubisi, N.O. Entrepreneurship: Its relationship with market orientation and learning orientation and as antecedents to innovation and customer value. Ind. Mark. Manag. 2011, 40, 336-345. [CrossRef]

33. Meng, N.N. Analysis of free marketing strategy based on customer transfer value theory. Mark. Mod. 2016, 32, 91-92.

34. O'Cass, A.; Ngo, L.V. Creating superior customer value for B2B firms through firm capabilities. Ind. Mark. Manag. 2012, 41, 125-135. [CrossRef]

35. Xie, X.M.; Shi, Q.Y. Empirical study on the factors influencing the transfer value of postal parcel service users in China. Technol. Econ. 2013, 9, 90-95.

36. Huang, J.Q.; Chen, H.; Li, D.Y. Research on factors influencing the success of crowdfunding projects from the perspective of customer value. China Soft Sci. 2015, 16, 116-127.

37. $\mathrm{Hu}, \mathrm{P}$. Research on the Competitive Advantage of Telecom Operators based on Customer Value in the 3G era. Master's Thesis, University of Electronic Science and Technology of China, Chengdu, China, 2012.

38. Xiao, L.J.; Yu, X. Optimization direction and strategy selection of enterprise performance based on customer delivered value. Mod. Financ. Econ. 2007, 5, 62-67.

39. Xu, W.T. Research on the Improvement of Domestic Car Brand Competitiveness Based on Customer Transfer Value. Master's Thesis, Anhui University of Technology, Maanshan, China, 2012.

40. Yang, H.; Feng, Z.Y. Value creation mechanism of real estate value chain based on customer value. Mod. Manag. Sci. 2012, 5, 57-59.

41. Han, P. Customer transfer value analysis based on the theory of consumer surplus. Econ. Manag. 2009, 3, 87-91.

42. Guo, S.Y. Empirical Research on Experience Marketing of Catering Enterprises Based on Customer Transfer Value. Master's Thesis, Anhui University of Technology, Maanshan, China, 2010.

43. MAIGOO Networks. Top Ten Pure Electric Vehicles. Available online: China-10.com/top/410771.html (accessed on 16 June 2019).

44. Lan Bao. The High Price of Electric Vehicles Mainly Comes from Batteries, So How to Reduce Battery Costs? Available online: http://k.sina.com.cn/article_5861881615_15d65370f00100cv7z.html (accessed on 16 June 2019).

45. Yijianfeihong. Why do You Have to Push the "Separation of Vehicles and Bettery" to Consumers? Available online: http://news.m.yiche.com/hao/wenzhang/786474 (accessed on 18 June 2019).

46. Qian Zhan Industry Research Institute. Analysis on the profitability and development drivers of China's charging pile industry in 2018. China Electr. Equip. Ind. 2019, 3, 27-31, 34. 
47. Liang, L.Z. New-Energy Vehicles Battery Can Only Rent not to Buy, but “Separation of Vehicle and Electricity “just Looks very Beautiful? Available online: http://news.m.yiche.com/hao/wenzhang/786474 (accessed on 18 June 2019).

48. Peng, T.T. User experience is not good and there are problems in popularization of new energy vehicles. Bus. China 2017, 11, 57-61. 